\title{
Seasonal adaptation and short-term metabolic responses of Gelidium sesquipedale to varying light and temperature
}

\author{
P. Duarte, J. G. Ferreira \\ Dept of Environmental Sciences \& Engineering, Faculty of Sciences and Technology, New University of Lisbon, \\ P-2825 Monte de Caparica, Portugal
}

\begin{abstract}
The responses of Gelidium sesquipedale productivity, photosynthetic efficiency and respiration to changes in light and temperature were measured on plants acclimated to different light/temperature combinations simulating average winter and summer conditions at 2 different depths. Photosynthetic efficiency was reported relative to frond surface area computed by a method described in this study. Algal pigment contents were monitored during acclimation. Results suggest that seasonal acclimation to light and temperature may have a significant effect on photosynthetic efficiency and on the dependence of productivity on light and temperature. This effect may be the opposite of what is generally expected from acclimation to photon flux density alone but is in good agreement with previously reported results indicating an increase in photosynthetic efficiency in plants grown at higher temperatures. There is some evidence that temperature adaptation may compensate light adaptation through changes at physiological levels other than the pigmentary system. Significant seasonal effects on respiration, as well as a strong temperature dependence, are apparent. Winter acclimated plants had higher respiratory rates than summer acclimated ones. Among the former, plants acclimated to the greater depth exhibited lower respiratory rates than those acclimated to the shallower depth, which is an important adaptation for surviving under low light conditions by reducing energetic losses. The compensation photon flux density values obtained in this work for $G$. sesquipedale suggest that during winter the average net photosynthesis may be negative for a significant part of its subtidal populations.
\end{abstract}

KEY WORDS: Acclimation · Light · Productivity - Respiration - Temperature

\section{INTRODUCTION}

The responses of algae to various environmental factors such as photon flux density, temperature or nutrients can be analysed on different time scales. The phenotypic adaptations to different levels of physical and chemical factors occurring, for example, at different depths or seasons are usually termed long-term responses or acclimation. The metabolic responses to rapid changes in any parameters are usually designated as short-term responses (Davison 1991). Whilst long-term responses are observed on a time scale of days/weeks, short-term responses are observed on a time scale of minutes/hours. Short-term responses are related to the long-term ones because, by adapting differently, algae may also respond differently to rapid changes in environmental parameters.
Several workers have studied the acclimation of macroalgae to various levels of photon flux density, temperature or nutrients (e.g. Ramus et al. 1976a, Santelices 1978, Beer \& Levy 1983, Fredriksen \& Rueness 1989). However, information concerning the adaptative changes related to seasonal phenomena, considering the synergistic action of several parameters, is very scarce. Furthermore, in acclimation studies it is not always clear if the levels chosen for the ecological factors are likely to occur in the habitat of the species under study. The short-term responses of algae to different environmental variables have also been studied (e.g. Cloern 1977. Algarra \& Niell 1990, Torres et al. 1991). Some authors analysed the acclimation effects on short-term responses (Ramus et al. 1976b, 1977, Beer \& Levy 1983). The quantitative changes in photosynthetic pigments are often used to 
assess the long-term responses of algae to different environmental conditions because of the importance of the pigments in primary productivity and their rapid response to changes in photon flux density, temperature or nutrient levels. Concerning the short-term responses, the most often measured parameters are productivity and photosynthetic efficiency.

Photosynthetic efficiency is measured as the initial slope of the $P$ versus $I$ curves. Productivity is usually expressed on a dry weight basis and photon flux density on an area basis. Therefore, photosynthetic efficiency has the dimensions of $\mathrm{mgC} \mathrm{g}^{-1} \mathrm{~mol}^{-1}$ photons $\mathrm{m}^{-2}$. Efficiency is often calculated on the basis of the light reaching the place where the plant stands instead of being calculated on the basis of the light actually received by the plant. The light received by the plant is proportional to its surface area. By relating biomass to thallus surface area and expressing productivity on an area basis, photosynthetic efficiency can be expressed in $\mathrm{mg}$ or mmol $\mathrm{C} \mathrm{mol}^{-1}$ photons actually reaching the plant surface. This way, for the same photon flux density, efficiency will depend solely on the physiological capacity of the plant to convert light into chemical energy.

In this work a methodology to estimate the whole surface area of macroalgae is described. This methodology has been tested on Gelidium sesquipedale but it is widely applicable to other species of different morphology, with particular relevance to algae with branched thalli. Algarra \& Niell (1987) proposed a methodology which allows the calculation of the surface area perpendicular to the bottom in algal stands. Minitcheva \& Eremenko (1986) developed an accurate but also time-consuming method consisting of determination of the whole surface area of the different parts of the thallus of branched algae. The areas were calculated from measurements of the length and diameter at the apical, medium and basal levels of the algae with a cylindrical cross section.

Gelidium sesquipedale was chosen for this study because of its economic importance as a raw material for the agar industry (Santos \& Duarte 1991). The data presented in this work is being used for the development of a management model (e.g. Duarte \& Ferreira 1993). In spite of the considerable number of works published on the genus Gelidium (for a review see Santelices 1988), there is no available information allowing a quantitative assessment of the productivity of $G$. sesquipedale as a function of such important environmental variables as photon flux density and temperature. The objectives of this work were (1) to evaluate the influence of different seasonal conditions on the pigment composition of $G$. sesquipedale, (2) to analyse and quantify the short-term responses of $G$. sesquipedale productivity, photosynthetic efficiency, respiration and exudation as a function of photon flux density and/or temperature and (3) to evaluate the influence of seasonal adaptation on the short-term responses of $G$. sesquipedale metabolism.

\section{METHODS}

Sampling and treatment. Gelidium sesquipedale fronds were collected at Cape Espichel (west coast of Portugal) at $10 \mathrm{~m}$ depth during spring 1993. The algae were kept in the laboratory for over 3 wk under stable water temperature, photoperiod and photon flux density (during daylight hours). Four acclimation pre-treatments were employed during this time: 2 simulating local winter conditions and 2 simulating summer conditions. The temperature was kept at $14.5^{\circ} \mathrm{C}$ in 2 pre-treatments (winter) and at $18.5^{\circ} \mathrm{C}$ in the other 2 (summer), with a photoperiod of 11.5 and $14.5 \mathrm{~h}$ respectively. Each pair of winter and summer pre-treatments differed only in the photon flux density used, reproducing approximately the average light conditions at 9 and $13 \mathrm{~m}$ depth: 9.4 and $4.4 \mathrm{mmol} \mathrm{m}^{-2} \mathrm{~s}^{-1}$ in the winter pre-treatments and 16.1 and $10.5 \mathrm{mmol} \mathrm{m}^{-2} \mathrm{~s}^{-1}$ in the summer pre-treatments, respectively. These depths are reported relative to the hydrographic zero and correspond to average real depths of approximately 11 and $15 \mathrm{~m}$ due to tidal effects The photoperiods and temperatures simulated the average winter and summer conditions in the area where the algae were sampled.

To estimate the underwater light intensity, a model was developed to simulate the tidal height variation and calculate the optical path between the surface and the desired depth, using a time step of $1 \mathrm{~h}$. The optical path was computed from depth and angles of incidence and refraction of the sun according to Rable (1985). The light intensity was calculated according to the Lambert-Beer law, from surface radiation, optical path and average water extinction coefficient, after discounting for reflection by the sea surface and for non-photosynthetic radiation. The extinction coefficients were based on Secchi disk and LiCor (Spherical quantum sensor LI-193SB) readings. The surface radiation data were also obtained with a spherical quantum sensor. A full description of the model is given in Ferreira \& Ramos (1989) and Duarte \& Ferreira (1993).

During the acclimation, approximately $200 \mathrm{~g}$ (fresh wt) of Gelidium sesquipedale fronds were kept in $200 \mathrm{l}$ tanks. The water in the tanks was in permanent circulation and was pumped from a common reservoir to avoid any non-controlled differences among the tanks. The flow rate was $200 \mathrm{l} \mathrm{h}^{-1}$. Every other day, the water was partially exchanged with sea water (about 120 l). Nutrient levels, $\mathrm{pH}$, salinity and temperature were monitored every second day and remained approxi- 
mately constant during the course of the experiment. Temperature varied no more than $1^{\circ} \mathrm{C}$ during the water exchanges; $\mathrm{pH}$ values were always close to 8.2 . Algal growth during acclimation was monitored by tagging and measuring the main axis lengths of approximately 30 algal fronds in each of the acclimation tanks. The tags used were described in Sharp \& Trembley (1985). In the pre-treatments and incubation experiments daylight fluorescent lamps (Philips Colour/96 'TL'D) were used. The regulation of the light flux was done by a manual potentiometer connected to the lamps through a high-frequency electronic ballast. Photon flux density was measured with a spherical quantum sensor (LI-193SB).

During the first $12 \mathrm{~d}$ of acclimation algal samples for pigment analysis were taken in triplicate from each tank every second day. Later on, sampling was carried out at a lower frequency. All samples were collected in triplicate and always at the same time of the day (09:30 h). Algal samples were immediately frozen for later analysis. Algae were macerated under liquid nitrogen. Chlorophyll a (chl a) was analysed after extraction with acetone and phycobilins after extraction and centrifugation in phosphate buffer $(\mathrm{pH}=6.8)$ (Rowan 1989). The equations of Talling \& Driver (1963) were used to calculate chl a concentration. Rphycoerithrin content was calculated using the equations of Beer \& Eshel (1985).

After the acclimation, algal samples collected at random from each of the acclimation tanks were incubated in $1000 \mathrm{ml}$ jars in an incubation chamber and submitted to various combinations of temperature and photon flux density according to a completely orthogonal sampling design (Underwood 1981). Productivity and respiration were measured from oxygen differences by the light-dark bottle technique (Vollenweider 1974). The temperatures tested were 11, 14, 18, 22 and $26^{\circ} \mathrm{C}$. At each of these temperatures, respiration was measured in the dark and productivity was measured at the light intensities 2, 4, 97, 206 and $270 \mu \mathrm{mol}$ photons $\mathrm{m}^{-2} \mathrm{~s}^{-1}$. It was not possible to replicate the acclimation pre-treatments. Because of this constraint, any significant differences between the metabolic rates of the plants taken from the different tanks cannot be proved to be solely a consequence of the differences amongst pre-treatments: there may be some unaccounted 'tank effect' (Hulbert 1984).

Prior to incubation, the algae were kept for $30 \mathrm{~min}$ under the light/temperature which was to be tested. In the incubation chamber the flasks stood on a rotating platform which was kept in permanent motion (about $60 \mathrm{rpm})$ during the experiments. For each light/ temperature combination, 3 replicates and a control were used. Each of the replicates consisted of several whole thalli in order to compensate for the natural intra- specific physiological variability (Littler 1980). Therefore, from each acclimation tank, 5 sets of respiration results (at each of the 5 temperatures) and 25 sets of productivity results (5 temperatures $\times 5$ light intensities) were obtained. Incubation times and biomasses were chosen so as to prevent inhibition of photosynthesis by an excess of dissolved oxygen, $\mathrm{pH}$ changes or nutrient depletion and to simultaneously assure that any oxygen changes would be detectable (Dromgoole 1978a, b, Littler 1979, Duarte 1990). The incubation times were about $1 \mathrm{~h}$ for productivity measurements and $1.5 \mathrm{~h}$ for respiration measurements. The incubated biomasses were approximately $1 \mathrm{~g}$ dry $\mathrm{wt}^{-1}$.

After the incubation period, 2 water samples from each replicate were collected for dissolved oxygen determination (Winkler method). The algae used in each experiment were blotted dry and dried at $75^{\circ} \mathrm{C}$ to constant weight, allowed to cool and weighed. A photosynthetic quotient of 1.2 and a respiratory quotient of 0.8 were used in the conversion of oxygen to carbon according to Vollenweider (1974) and Geider \& Osborne (1989). Exudation rates were estimated in the acclimation tanks by the method of Khailov \& Burlakova (1969). Algae were incubated in light and dark $1000 \mathrm{ml}$ incubation flasks within the acclimation tanks. A light and a dark control were also used. After 5 to 6 h of incubation, water samples were taken from the incubation flasks and the dissolved organic matter (DOM) content determined from their absorbance at $260 \mathrm{~nm}$, as described by the previous authors Released DOM was converted to carbon assuming an average carbon content of $42.2 \%$ (w/w) (Duarte unpubl.). The respiration data obtained were analysed by 2 -way ANOVA with replication. The main effects to be tested were the acclimation pre-treatment and the temperature. The null hypotheses tested were (1) the average respiration results obtained with algae sampled from the 4 tanks are identical, (2) the average respiration results obtained with algae incubated at the tested temperatures are identical, and (3) there is no significant interaction effect between acclimation tanks and temperature on the respiratory rates of the algae.

A model of productivity as a function of photon flux and temperature based on Eilers \& Peeters (1988) and on a temperature function (Eq. 1) was used to fit a response surface to the results obtained with algae from each of the acclimation pre-treatments:

$$
P=\frac{I \exp (d-e / t)}{a I^{2}+b I+c}
$$

where $P$ is gross primary productivity, $I$ is photon flux density, $t$ is temperature, $a, b$ and $c$ are parameters of the light dependent function (see Eilers \& Peeters 1988 
and Duarte in press), and $d$ and $e$ are parameters of the temperature dependent function (see Duarte in press). For details regarding model fitting see Duarte (in press). The 4 fitted surfaces were compared by $F$ ratios as described in Mead \& Curnow (1983) and Potvin \& Lechowicz (1990). A surface was obtained by grouping all the data; the $F$ ratio between the increase in the mean residual sum of squares, resulting from grouping all the data, and the mean residual sum of squares of the 4 fitted surfaces was computed. This procedure was carried out to test the null hypothesis that the increase in the average residual sum of squares obtained by grouping the data and fitting one surface to it is not significant. In a similar way, further comparisons were carried out between the winter and summer pre-treatments and between those simulating 9 and $13 \mathrm{~m}$ depth.

Photosynthetic efficiency is computed from the derivative of Eq. (1) when photon flux approaches 0 . The obtained values were reported relative to thallus surface area (see below). The model predicts that the quantum efficiency is temperature dependent, which is in accordance with recent physiological data (Davison 1991).

Thallus area determination. Gelidium sesquipedale fronds of more than 6 to $8 \mathrm{~cm}$ are usually branched. Plants can reach more than $30 \mathrm{~cm}$ in length and branching is usually proportional to size, occurring mainly to the sides of the main axis (Figs. 1 \& 2). The cross section of the thallus is semicircular or elliptical over the whole plant body. The measurement of the surface area of a thallus of this type is problematic. The methodology developed in this work consists of (1) obtaining digitised images of the thalli by scanning them into bitmap files using a flatbed scanner, (2) calculation of areas using an appropriate algorithm, based on the pixels composing the image, and (3) application of a correction to account for the curvature of the thallus allowing the calculation of the whole surface area of the plant.

In a first approach to estimating the surface area of the fronds it is assumed that their cross section is rectangular (Fig. 2). Therefore the total surface frond area is obtained as

$$
A_{\text {rec }}=2 \times C\left(l_{1}+l_{2}\right)
$$

where $A_{\text {rec }}$ is total area assuming a rectangular cross section, $C$ is the sum of the length of all axes and branches, $I_{1}$ is the average width of the rectangle's major side (Fig. 2), $I_{2}$ is the average width of the rectangle's minor side (Fig. 2).

When a Gelidium sesquipedale thallus is placed on a surface, the visible area $\left(A_{1}\right)$ equals $C \times I_{1}$ (Figs. 1 \& 2). By digitising the image of the algae corresponding to $A_{1}$ with a flatbed scanner and storing the obtained image (Fig. 1) in a bitmap file, it is possible to count the

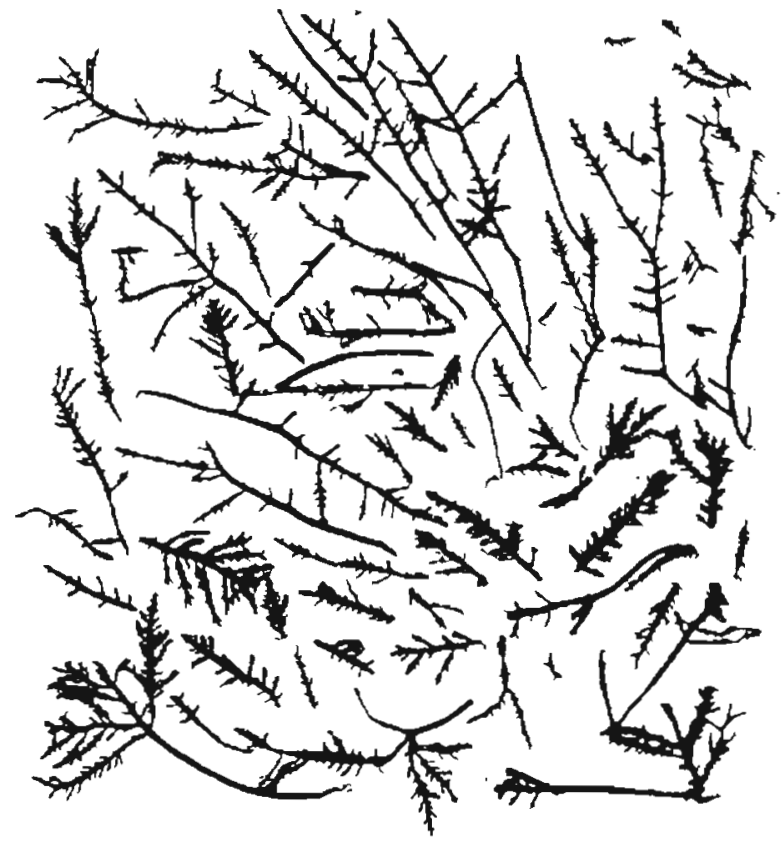

Fig. 1. Gelidium sesquipedale. Image obtained by scanning fronds

number of pixels occupied by it and to evaluate their total area. The reading of the bitmap files and the computation of their area was carried out with the computer program BitWin (Vicente unpubl.).

The remaining 'theoretical' area $\left(A_{2}\right)$ can be calculated from the ratio $l_{1}: I_{2}$ which equals the ratio $A_{1}: A_{2}$ since $C$ is the same for both areas. This ratio was estimated by cutting random thalli collected over several months and measuring $l_{1}$ and $l_{2}$ for each of the cut pieces. The average, 0.2958 , calculated for more than 200 measurements, was used to compute $l_{2}$ from $l_{1}$ and $A_{2}$ from $A_{1}$. Knowing $A_{1}$ and $A_{2}, A_{\text {rec }}$ can be calculated as

$$
A_{\text {rec }}=2\left(A_{1}+A_{2}\right) \text {. }
$$

The result obtained in Eq. (3) must be corrected since the cross section of the plant is elliptic. This

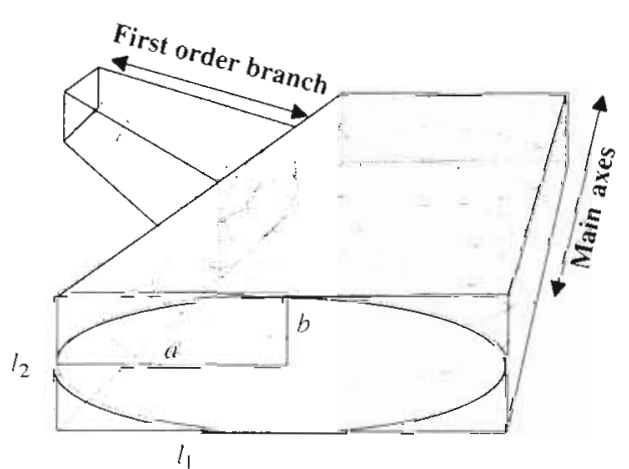

Fig. 2. Schematic representation used in determination of thallus area (see 'Methods' for explanation) 
correction is based on the knowledge of the ratio between the perimeter of a rectangle $\left(P_{\text {rec }}\right)$ with sides $l_{1}$ and $l_{2}$ and the perimeter of an ellipse $\left(P_{\text {ellip }}\right)$ with axes $a$ and $b$ (Fig. 2). This ratio equals the ratio between the $A_{\text {rec }}$ and $A_{\text {ellip }}$ - the area of the fronds assuming an elliptic cross section - since the area is the perimeter multiplied by $C$, and $C$ is the same under both assumptions

$$
\begin{aligned}
P_{\text {rec }} / P_{\text {ellip }} & =2(2 a+2 b) / \pi(a+b) k \\
& =A_{\text {rec }} / A_{\text {ell }} \quad(\text { Perry 1950) }
\end{aligned}
$$

where

$$
k=1+1 / 4[(a-b) /(a+b)]^{2}+1 / 64[(a-b) /(a+b)]^{4}+\ldots
$$

or

$$
\begin{aligned}
k=1 & +1 / 4[(1-b / a) /(1+b / a)]^{2} \\
& +1 / 64[(1-b / a) /(1+b / a)]^{4}+\ldots
\end{aligned}
$$

and where $b / a$ equals $l_{2} / l_{1}$ which was determined empirically (see above). From Eq. (4)

$$
A_{\text {ellip }}=A_{\text {rec }} \pi(a+b) k /(4 a+4 b) .
$$

Dividing the numerator and the denominator by $a$

$$
A_{\text {ellip }}=A_{\text {rec }} \pi(1+b / a) k /(4+4 b / a) .
$$

From Eq. (3) and knowing that

$$
A_{2}=A_{1} b / a
$$

the following is obtained

$$
A_{\text {rec }}=2 A_{1}(1+b / a)
$$

By combining Eqs. (8) and (10) the final formula is

$$
A_{\text {ellip }}=2 A_{1}(1+b / a) \pi(1+b / a) k /(4+4 b / a) .
$$

The above procedures were carried out on several samples which were then dried to constant weight. In Fig. 3, a regression analysis between dry weight and thallus surface area is shown. The regression equation is significant (Fig. 3) and was used to allow a fast estimation of thallus areas from dry weights

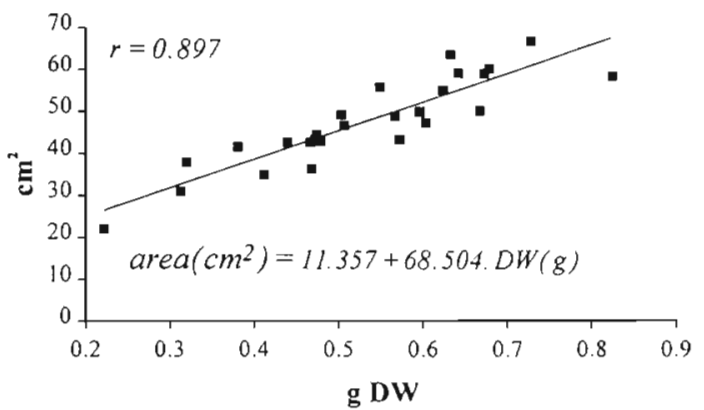

Fig. 3. Gelidium sesquipedale. Regression line between dry weight and frond surface area $(p<0.001)$

\section{RESULTS AND DISCUSSION}

From Fig. 4 a it can be seen that after a period of 10 to $14 \mathrm{~d}$ of acclimation to winter conditions, the mean chl a content appears to show a tendency to increase until the end of the experiment, probably as a response to the low photon flux density and short photoperiod. This tendency was apparent for both simulated depths and was confirmed by regression analysis (slope significantly greater than 0 in both cases; $p<0.05$ ). However, the result of a $t$-test to compare the mean values of all replicates measured before and after Day 10 do not demonstrate any significant differences at the $95 \%$ confidence level, except for the results obtained with the algae acclimated to the shallower depth $(9 \mathrm{~m})$.

In Fig. 4b chl a content does not appear to show any trend with time. This was confirmed by regression analysis, which led to a slope not significantly different from zero $(p>0.05)$. As regards $R$-phycoerythrin (Fig. 5a, b) no trends were observed during the course of the experiments. In all regression analyses the slopes obtained did not differ significantly from zero ( $p>0.05$ ). According to the work of Fredriksen \& Rueness (1989) on Gelidium latifolium, the absence of diminishing trends in R-phycoerythrin demonstrates that nitrogen limitation did not occur. The differences between the average pigment contents at the 2 simulated depths were nonsignificant ( $t$-test, $p>0.05$ ) in both winter and summer conditions for chlorophyll and
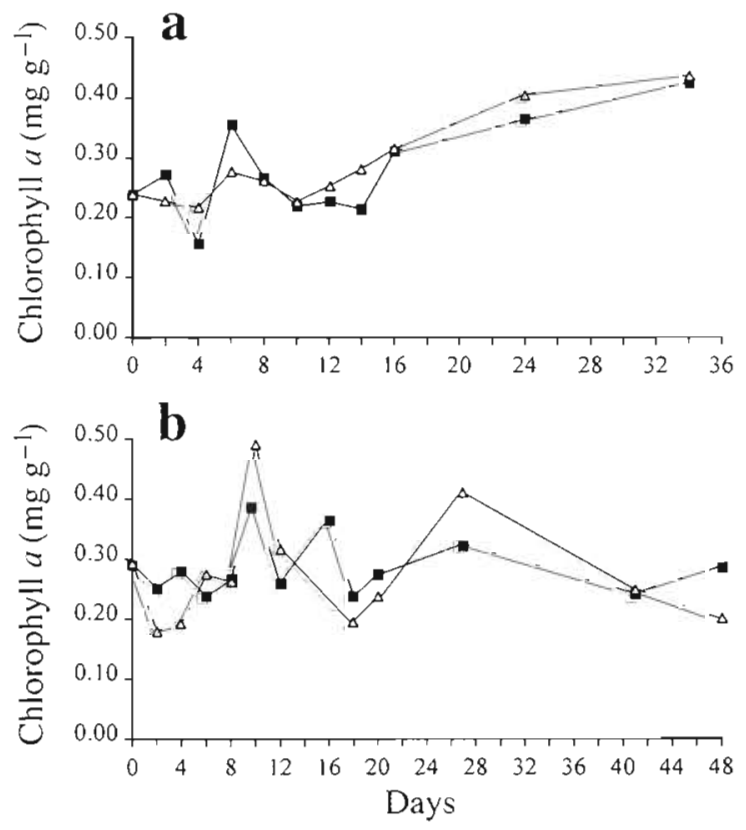

Fig. 4. Gelidium sesquipedale. Chl a variation as a function of time. Pre-treatments corresponding to $13(-)$ and $9 \mathrm{~m}(\Delta)$ depth in (a) winter and (b) summer conditions. Each value is the mean of 3 replicates. 95\% confidence limits are of the same magnitude as the mean 


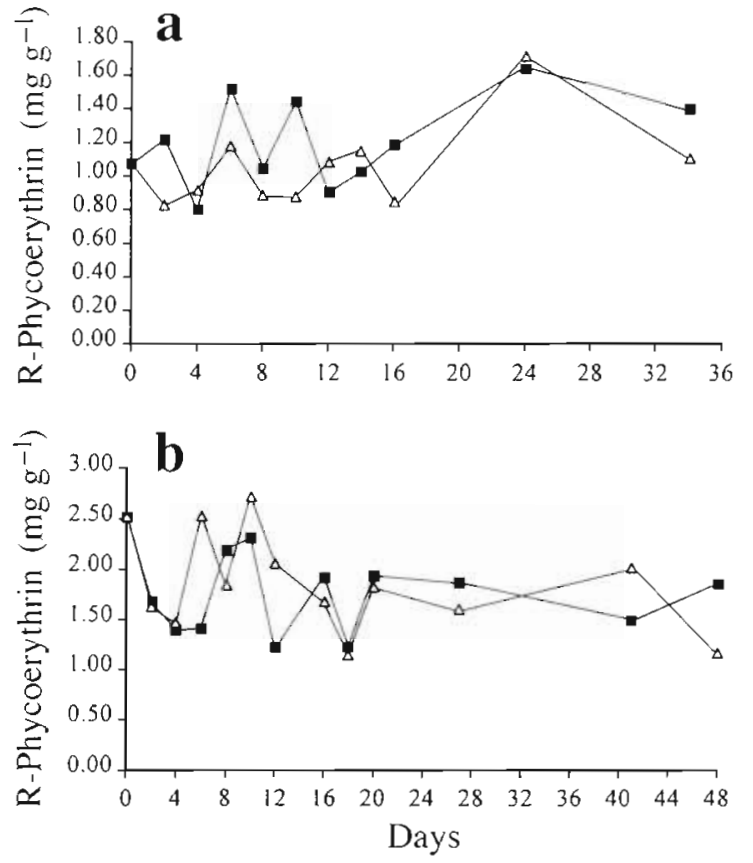

Fig. 5. Gelidium sesquipedale. R-phycoerythrin variation as a function of time. Pre-treatments corresponding to $13(-)$ and $9 \mathrm{~m}(\Delta)$ depth in (a) winter and (b) summer conditions. Each value is the mean of 3 replicates. $95 \%$ confidence limits are of the same magnitude as the mean

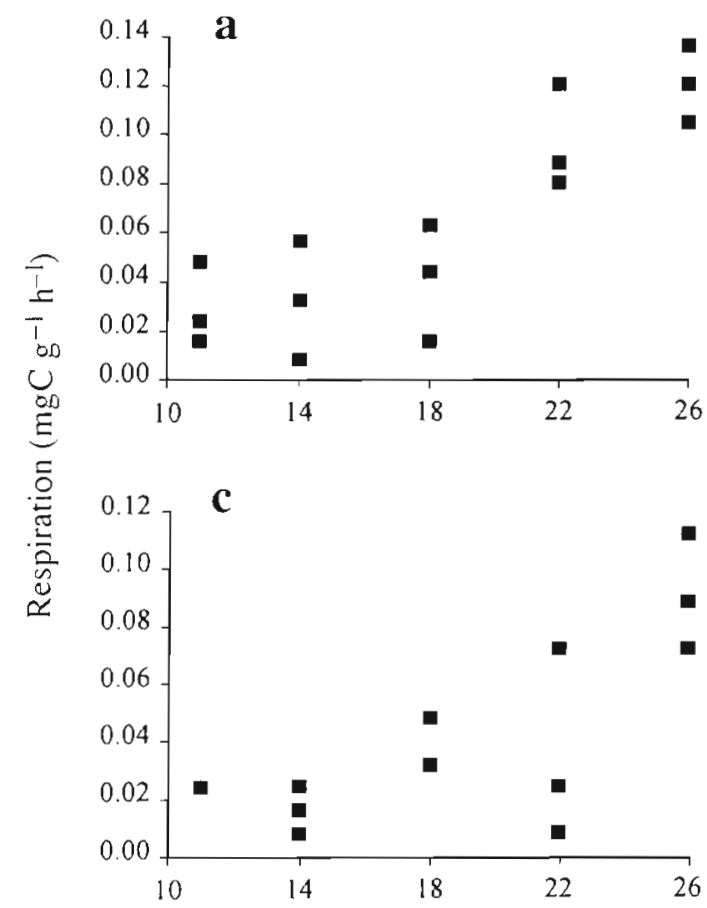

Table 1. Two-way ANOVA Model I with replication on the measured respiration rates obtained from Gelidium sesquipedale

\begin{tabular}{|lcrrrr|}
\hline Effects & $\begin{array}{c}\text { Sum } \\
\text { of squares }\end{array}$ & df & $\begin{array}{c}\text { Mean sum } \\
\text { of squares }\end{array}$ & $F$ & $p$ \\
\hline Acclimation & 0.0270 & 3 & 0.0090 & 14.1866 & $1.92 \times 10^{-6}$ \\
Temperature & 0.0878 & 4 & 0.0219 & 34.6460 & $1.67 \times 10^{-12}$ \\
Interaction & 0.0230 & 12 & 0.0019 & 3.0201 & 0.0043 \\
Error & 0.0253 & 40 & 0.0006 & & \\
Total & 0.1631 & 59 & & & \\
\hline
\end{tabular}

phycoerythrin. After the first 2 wk of acclimation, the mean values of chl $a$ and $\mathrm{R}$-phycoerythrin in the plants of all treatments were not significantly different ( $t$-test, $\mathrm{p}>0.05$ ).

In Table 1, the results of a 2-way ANOVA Model I with replication to test the independent and interaction effects of temperature and acclimation on the measured respiration rates are shown. As can be seen, both the independent and interaction effects are significant. These results provide evidence of the importance of seasonal acclimation on the respiration responses at different temperatures. In Fig. 6 the respiratory rates obtained at the 5 tested temperatures and with algae from the 4 acclimation pre-treatments are presented.
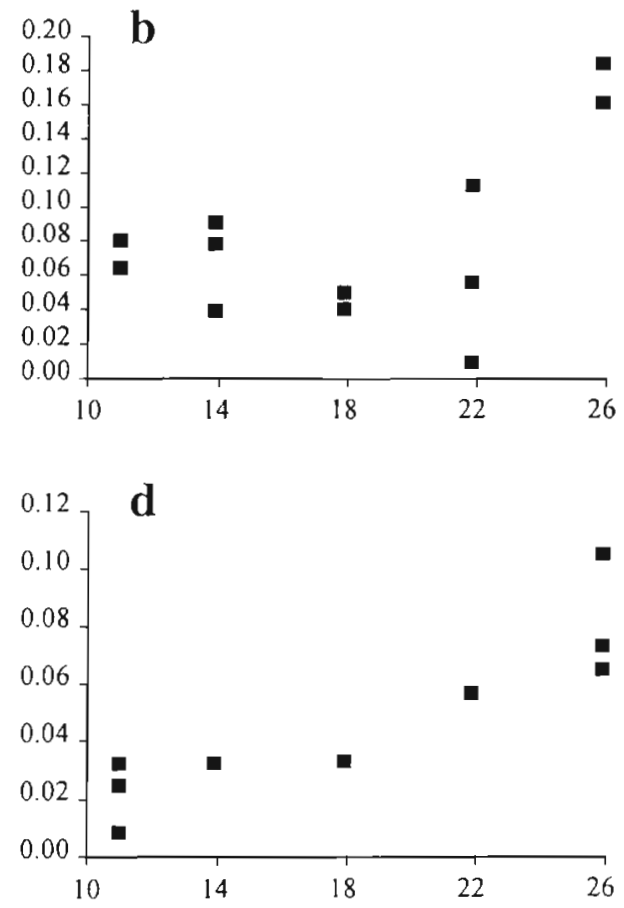

Temperature $\left({ }^{\circ} \mathrm{C}\right)$

Fig. 6. Gelidium sesquipedale. Respiratory rates measured at 5 different temperatures with algae acclimated to different conditions. Results obtained with ( $a, b)$ algae acclimated to winter conditions and a simulated depth of (a) 13 and (b) 9 m, and (c, d) algae acclimated to summer conditions and a simulated depth of (c) 13 and (d) $9 \mathrm{~m}$ 
Table 2. Newman-Keuls test results to compare the average respiration rates (values in parentheses in $m g \mathrm{Cg}^{-1} \mathrm{~h}^{-1}$ ) obtained with Gelidium sesqupedale from the 4 pretreatments. Values in bold correspond to non-significant differences $(p>0.05)$

\begin{tabular}{|c|c|c|c|c|}
\hline Pre-treatment & $1(0.06)$ & $2(0.08)$ & $3(0.04)$ & $4(0.04)$ \\
\hline Winter & & 0.00922 & 0.01307 & 0.01231 \\
\hline $9 \mathrm{~m}$ & 0.00922 & & 0.00017 & 0.00013 \\
\hline Summer $13 \mathrm{~m}$ & 0.01307 & 0.00017 & & 0.71889 \\
\hline $9 \mathrm{~m}$ & 0.01231 & 0.00013 & 0.71889 & \\
\hline
\end{tabular}

$P=I \exp (0.54-17.88 / t) /\left(0.002 I^{2}+0.009 I+130.142\right)$

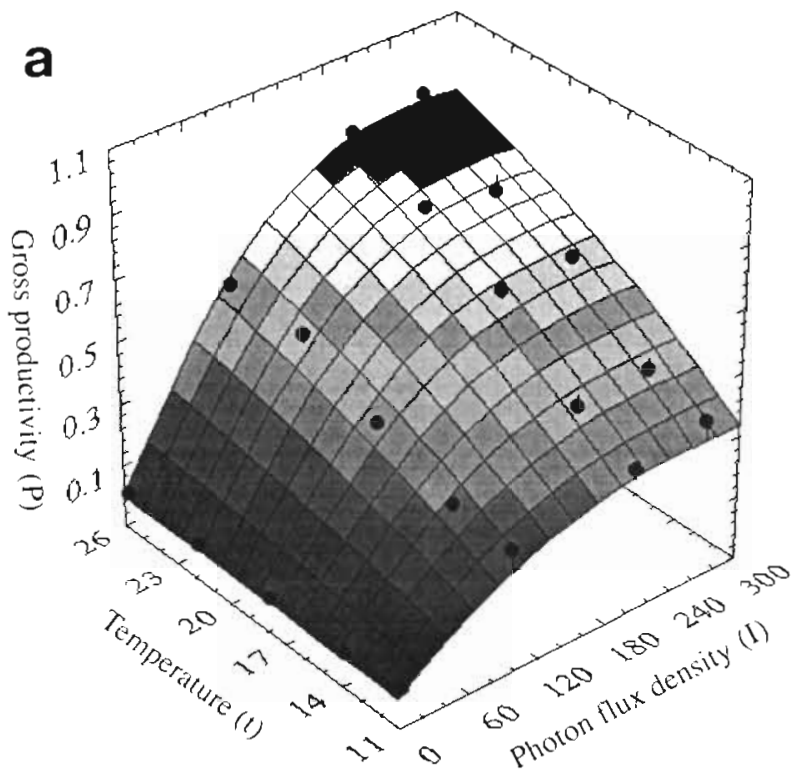

b

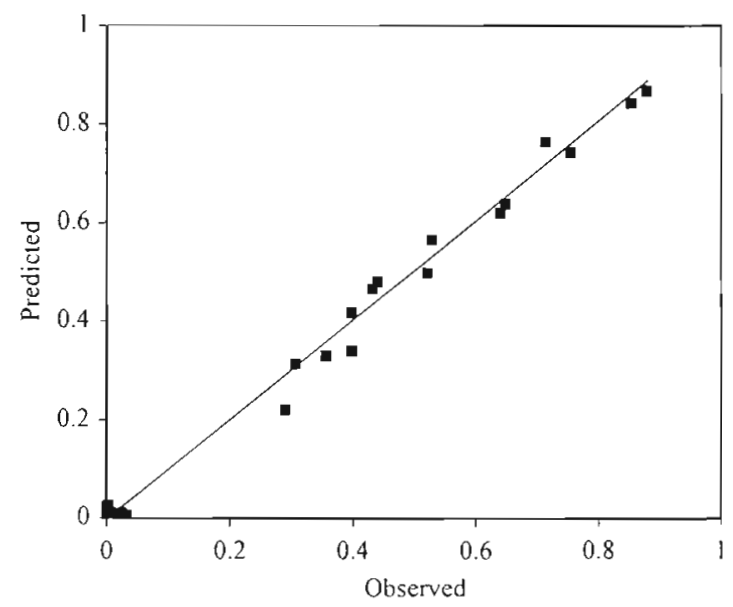

Fig. 7. Gelidium sesquipedale. (a) Model equation and fitted surface for data obtained with algae acclimated to winter conditions and $13 \mathrm{~m}$ depth. Minimal light intensity: $2 \mu \mathrm{mol}$ $\mathrm{m}^{-2} \mathrm{~s}^{-1}$ photons. (b) The slope of the regression line between observed and predicted values is not significantly different from 1 . The $y$-intercept is not significantly different from 0

$$
(p<0.05)
$$
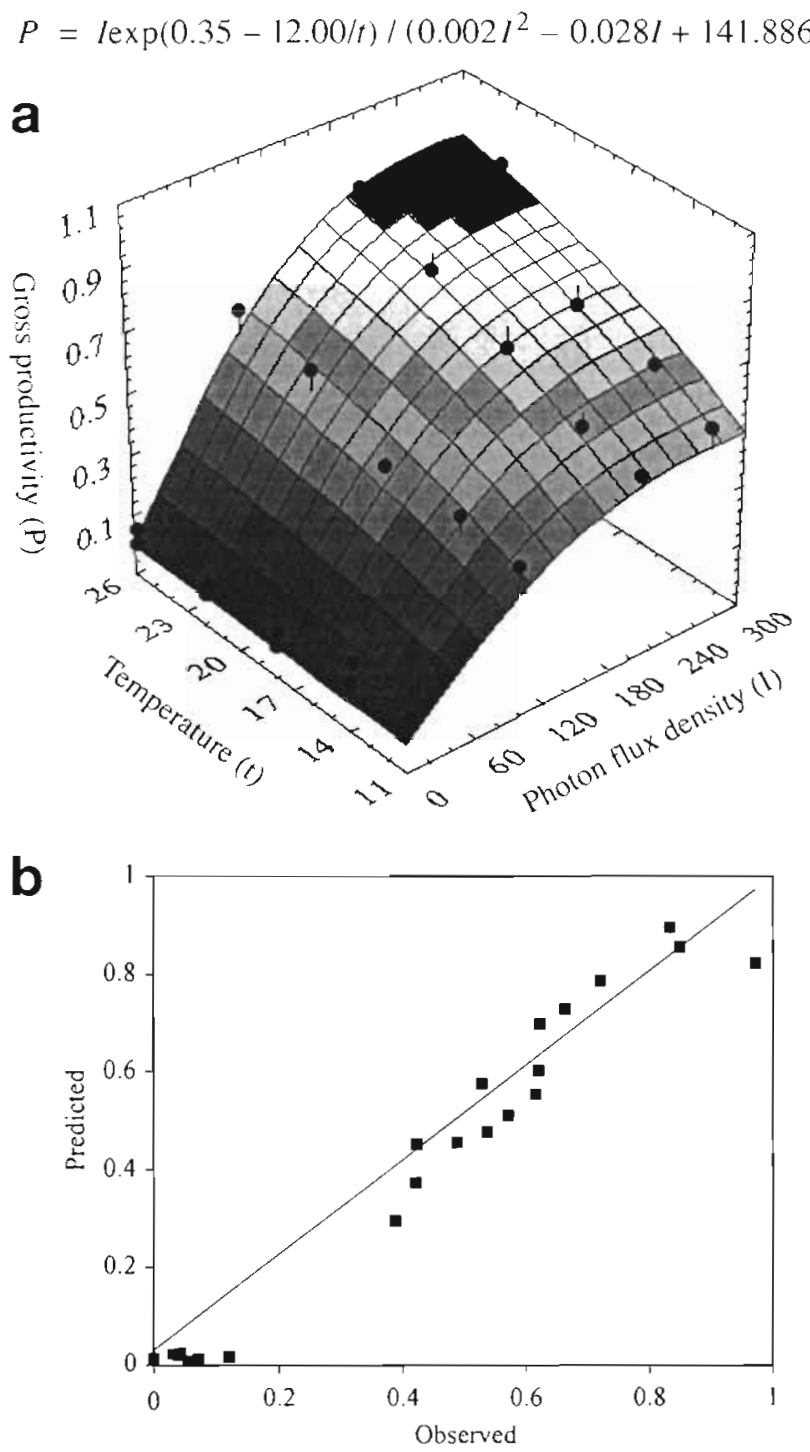

Fig. 8. Gelidium sesquipedale. (a) Model equation and fitted surface for data obtained with algae acclimated to winter conditions and $9 \mathrm{~m}$ depth. Minimal light intensity: $2 \mu \mathrm{mol}$ $\mathrm{m}^{-2} \mathrm{~s}^{-1}$ photons. (b) The slope of the regression line between observed and predicted values is not significantly different from 1 and the $y$-intercept is not significantly different from 0 $(\mathrm{p}<0.05)$

Predictably, there is a positive relationship between respiration and temperature (Kremer 1981). From the results of a Newman-Keuls test (Table 2) it can be seen that the average respiration rates obtained with plants acclimated into the 4 different treatments are all different, except those corresponding to the summer acclimations to 9 and $13 \mathrm{~m}$ depth. The lowest values from winter acclimated plants correspond to those kept at a simulated greater depth. This result agrees with the findings of Sand-Jensen (1988) on Ulva lactuca kept at low light. By reducing maintenance costs, 
$P=l \exp (0.86-19.18 / t) /\left(0.002 I^{2}-0.050 I+136.046\right)$
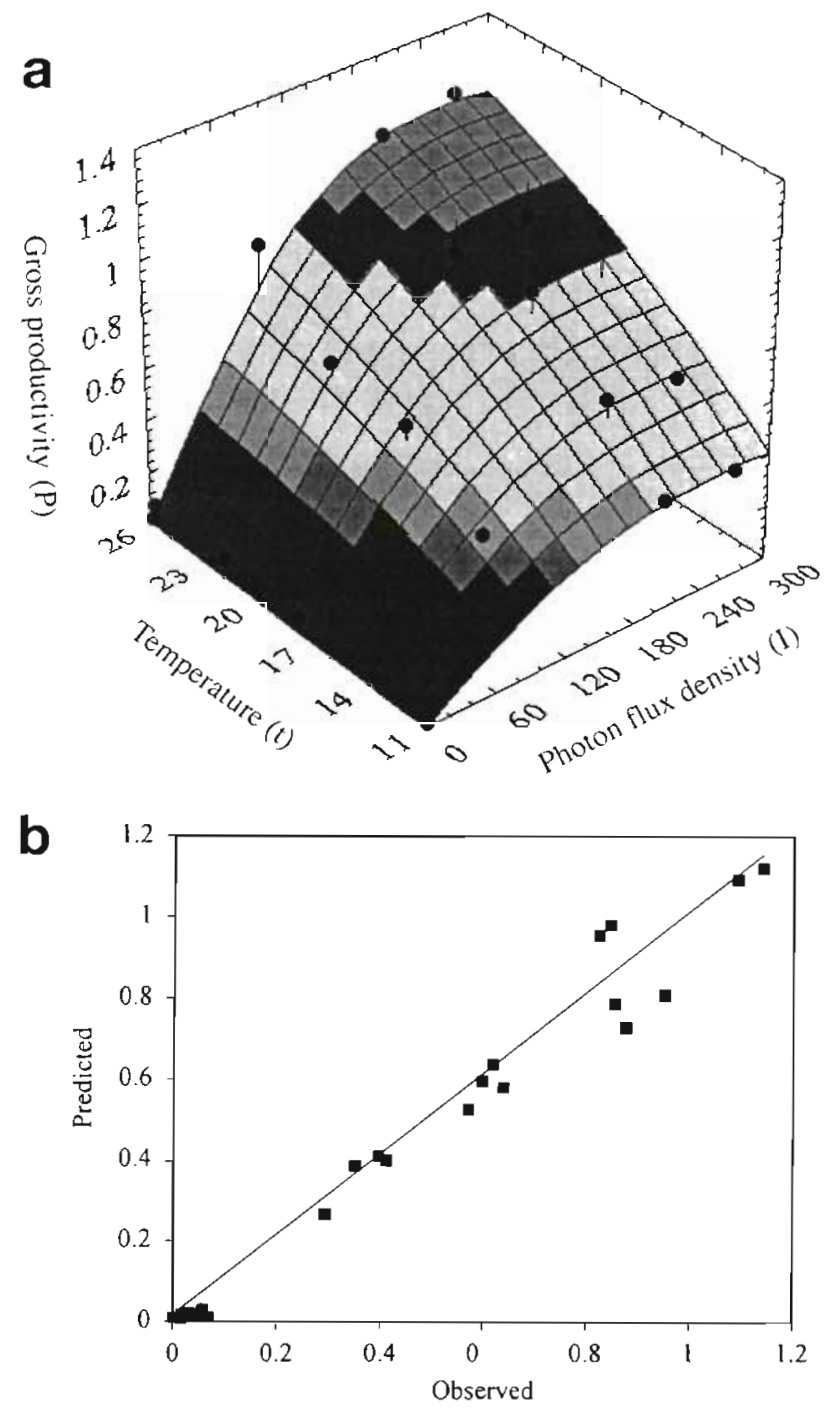

Fig. 9. Gelidium sesquipedale. (a) Model equation and fitted surface for data obtained with algae acclimated to summer conditions and $13 \mathrm{~m}$ depth. Minimal light intensity: $2 \mu \mathrm{mol}$ $\mathrm{m}^{-2} \mathrm{~s}^{-1}$ photons. (b) The slope of the regression line between observed and predicted values is not significantly different from 1 and the $y$-intercept is not significantly different from 0 $(p<0.05$

plants can survive longer periods under light intensities below the compensation point. In apparent contradiction with these findings are the lower respiration rates of summer acclimated plants. However, according to Kremer (1981), the respiration rates and corresponding $Q_{10}$ values of algae in winter are higher than those in summer when measured at the same temperatures.

In Figs. 7, 8, 9 \& 10 the surfaces obtained by fitting the model described in Duarte (in press) and regression lines between the measured and computed values

$$
P=I \exp (0.48-12.40 / t) /\left(0.002 I^{2}-0.018 I+131.796\right)
$$
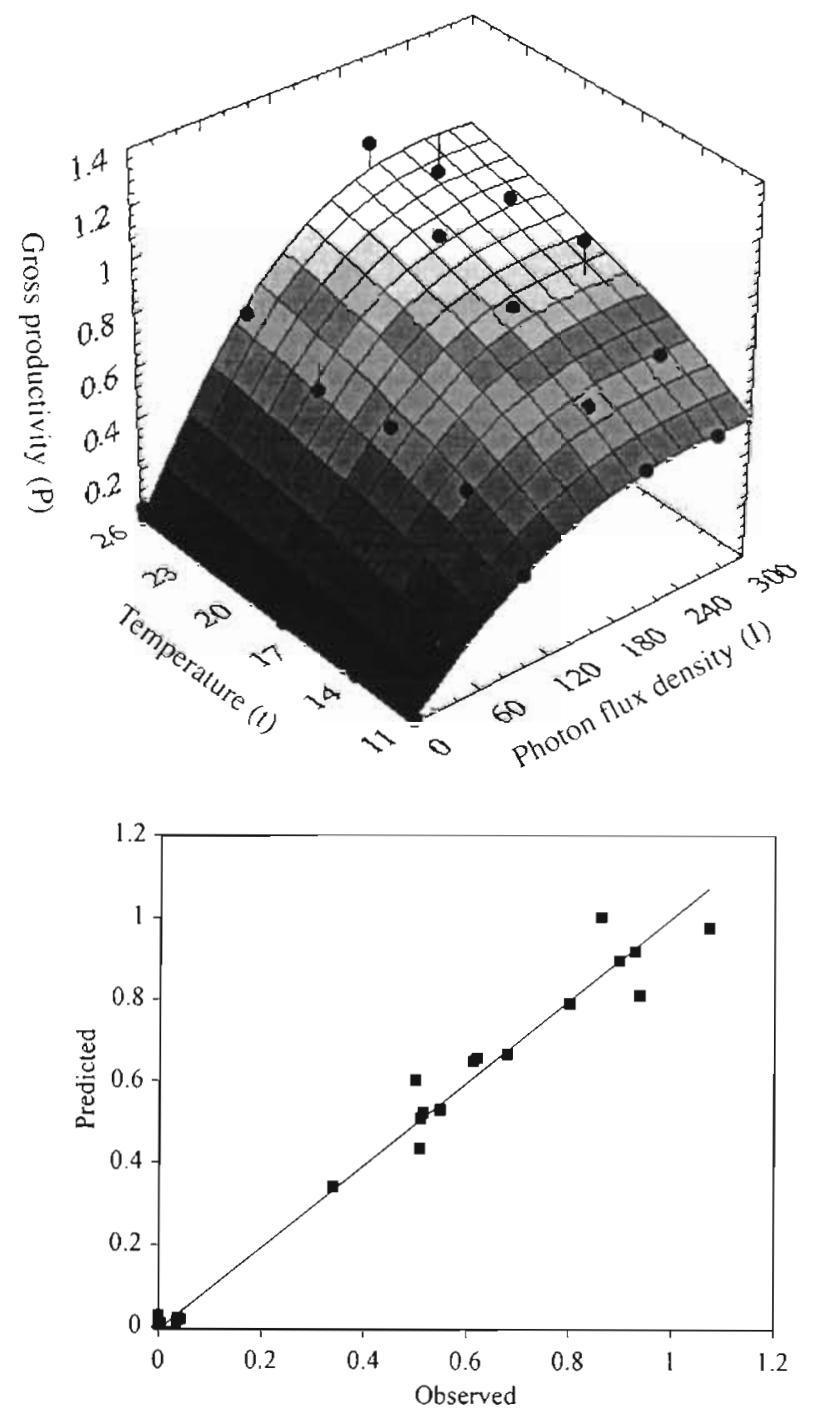

Fig. 10. Gelidium sesquipedale. (a) Model equation and fitted surface for data obtained with algae acclimated to summer conditions and $9 \mathrm{~m}$ depth. Minimal light intensity: $2 \mu \mathrm{mol}$ $\mathrm{m}^{-2} \mathrm{~s}^{-1}$ photons. (b) The slope of the regression line between observed and predicted values is not significantly different from 1 and the $y$-intercept is not significantly different from 0 $(p<0.05)$

are shown. Model II regression was used according to Laws \& Archie (1981) and following Sokal \& Rohlf (1981). The slopes of the regressions are not significantly different from 1 and the $y$-intercepts are not significantly different from zero $(\mathrm{p}<0.05)$, confirming the good quality of the model fitting (Keller 1989). Model equations are included in the figures. The summer acclimated algae exhibit higher maximal productivity rates than the winter acclimated ones.

Tables $3,4 \& 5$ summarise the results of the $F$-tests to compare the surfaces obtained by the 4 fittings. From 
Table 3. F-test to compare the mean square residuals obtained by fitting the model to all data points and by fitting the model to the results obtained with Gelidium sesquipedale from each of the 4 acclimations

\begin{tabular}{|c|c|c|c|c|c|}
\hline Pre-treatment & $\begin{array}{l}\text { Sum of } \\
\text { squared } \\
\text { residuals }\end{array}$ & $\mathrm{df}$ & $\begin{array}{l}\text { Mean } \\
\text { square } \\
\text { residuals }\end{array}$ & $F$ & $\mathrm{p}$ \\
\hline Winter $13 \mathrm{~m}$ & 0.0206 & 20 & & & \\
\hline $9 \mathrm{~m}$ & 0.0875 & 20 & & & \\
\hline Summer $13 \mathrm{~m}$ & 0.0984 & 20 & & & \\
\hline $9 \mathrm{~m}$ & 0.0679 & 20 & & & \\
\hline Total & 0.2745 & 80 & 0.0034 & & \\
\hline All data grouped & 0.5923 & 95 & & & \\
\hline All data grouped - Total & 0.3178 & 15 & 0.0212 & 6.1749 & $<0.001$ \\
\hline
\end{tabular}

Table 4. F-test to compare the mean square residuals obtained by fitting the model to all data points and by fitting the model to the results obtained with Gelidium sesquipedale from each of the seasonal acclimations

\begin{tabular}{|lrrrrr|}
\hline Pre-treatment & $\begin{array}{c}\text { Sum of } \\
\text { squared } \\
\text { residuals }\end{array}$ & df & $\begin{array}{c}\text { Mean } \\
\text { square } \\
\text { residuals }\end{array}$ & $F$ & $p$ \\
\hline Winter 13 and $9 \mathrm{~m}$ & 0.1467 & 45 & & & \\
Summer 13 and $9 \mathrm{~m}$ & 0.2111 & 45 & & & \\
Total & 0.3578 & 90 & 0.0040 & & \\
All data grouped & 0.5923 & 95 & & & \\
All data grouped - Total & 0.2346 & 5 & 0.0469 & 11.8026 & $<0.001$ \\
\hline
\end{tabular}

Table 5. F-test to compare the mean square residuals obtained by fitting the model to all data points and by fitting the model to the results obtained with Gelidium sesquipedale from each of the simulated depths

\begin{tabular}{|lcrccc|}
\hline Acclimation & $\begin{array}{c}\text { Sum of } \\
\text { squared } \\
\text { residuals }\end{array}$ & df & $\begin{array}{c}\text { Mean } \\
\text { square } \\
\text { residuals }\end{array}$ & $F$ & $\mathrm{p}$ \\
\hline Winter and summer $13 \mathrm{~m}$ & 0.3253 & 45 & & & \\
Winter and summer $9 \mathrm{~m}$ & 0.1960 & 45 & & & \\
Total & 0.5214 & 90 & 0.0058 & & \\
All data grouped & 0.5923 & 95 & & & \\
All data grouped - Total & 0.0710 & 5 & 0.0142 & 2.4496 & $<0.05$ \\
\hline
\end{tabular}

Table 6. Gelidium sesquipedale. Photosynthetic efficiency (mmol C mol-1 photons) for all the tested temperatures and acclimations

\begin{tabular}{|c|c|c|c|c|}
\hline \multirow[t]{2}{*}{$\begin{array}{l}\text { Temperature } \\
\left({ }^{\circ} \mathrm{C}\right)\end{array}$} & \multicolumn{2}{|c|}{$\begin{array}{c}\text { Winter } \\
\text { acclimation }\end{array}$} & \multicolumn{2}{|c|}{$\begin{array}{c}\text { Summer } \\
\text { acclimation }\end{array}$} \\
\hline & $13 \mathrm{~m}$ & $9 \mathrm{~m}$ & $13 \mathrm{~m}$ & $9 \mathrm{~m}$ \\
\hline 11 & 7.54 & 9.71 & 8.75 & 11.56 \\
\hline 14 & 10.68 & 12.27 & 12.72 & 14.72 \\
\hline 18 & 14.19 & 14.84 & 17.25 & 17.92 \\
\hline 22 & 16.99 & 16.76 & 20.93 & 20.34 \\
\hline 26 & 19.26 & 18.22 & 23.94 & 22.14 \\
\hline
\end{tabular}

the results presented in Table 1, it can be concluded that the null hypothesis on the absence of significant differences between the 4 surfaces must be rejected. In fact the increase in the mean square residuals obtained by fitting only 1 surface to all the data is significantly different from zero. The same kind of results is obtained when the overall surface is compared to surfaces fitted to each of the seasonal acclimations or to each of the simulated depths (Tables 4 \& 5). From these results it is possible to conclude that the response surfaces are different and cannot be described by the same function. Under the assumption that there were no uncontrolled effects in the acclimation tanks influencing the results significantly, it seems that both depth and season have a significant effect on those differences.

The maximal gross quantum efficiency at all the incubation temperatures, obtained from the model productivity estimates when photon flux density approaches zero, is shown in Table 6. The results obtained ranged between 7.54 and $23.94 \mathrm{mmol} \mathrm{C} \mathrm{mol} \mathrm{C}^{-1}$ photons. These values are close to the lower measurements obtained by Markager (1993) for the red alga Porphyra purpurea based on the ratio of gross photosynthesis to incident light. There is a significant temperature effect on the quantum efficiency, with the highest values corresponding to the highest temperatures and summer acclimations (Duarte in press).

Under natural conditions the Gelidium plant tends to have only one of its surfaces directly exposed to the light. The passing of the waves moves the algae around and shaded parts are periodically exposed to light flecks. In the measurements reported in this work, plants were also subjected to some self-shading due to the presence of several thalli in each incubation flask, leading to some underestimation of quantum efficiency. The constant motion of the flasks tended to expose some of the shaded parts to light. This way, experimental conditions had some similarity with natural ones. However, one should be aware of the fact that the degree of self-shading was probably different from field conditions and that the periodicity with which the shaded parts were directly exposed to light might also have differed. Under high light intensities which may cause photoinhibition, it is likely that the periodic shading of the thallus may pre- 


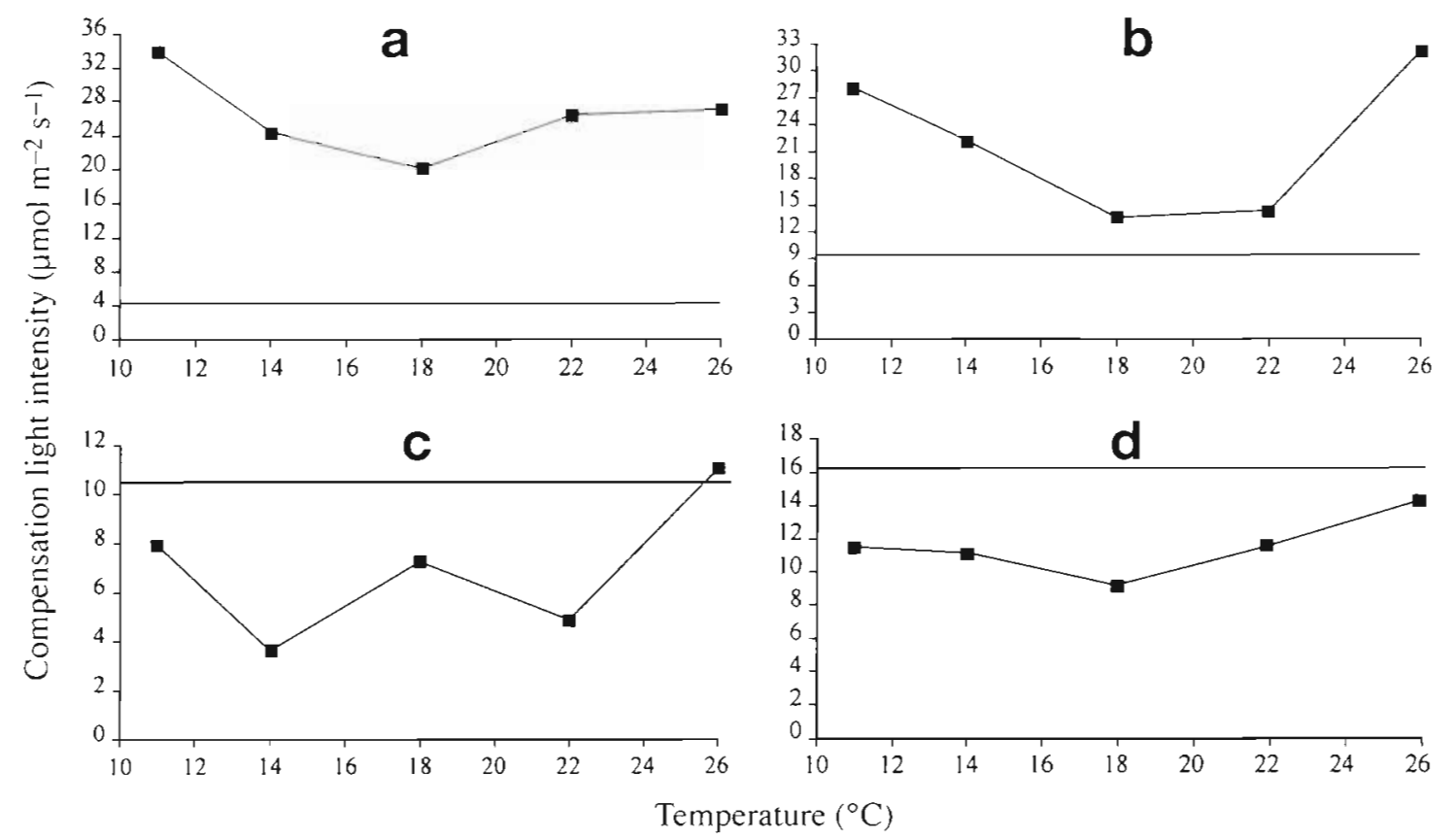

Fig. 11. Gelidium sesquipedale. Compensation light intensities as a function of temperature. Results obtained with algae acclimated to (a, b) winter conditions and a depth of 13 and $9 \mathrm{~m}$, respectively and (c, d) algae acclimated to summer conditions and a depth of 13 and $9 \mathrm{~m}$, respectively. Horizontal lines correspond to the average photon flux density at the sampling area (Cape Espichel) for the seasons and depths simulated

vent photoinhibition since it is known that photoinhibition is a time-dependent phenomenon (Platt et al. 1980, Eilers \& Peeters 1993). It has been demonstrated that in some algae and under periodicities close to those of the ocean swells ( 5 to 20 s) the light flecks may increase the photosynthetic rate relative to steady state conditions under the same lighting conditions (Wing \& Patterson 1993).

The average exudation rate is $0.03 \mathrm{mg} \mathrm{Ch}^{-1} \mathrm{~g}^{-1}$ (dry $\mathrm{wt}$ ) which is close to the lowest values measured by Khailov \& Burlakova (1969). No significant differences were observed between light and dark exudation rates. From Eq. (1), and the respiration and exudation rates obtained in this work, the compensation photon flux density for growth was estimated by solving Eq. (12) in relation to $I$ with net primary productivity set to zero. The result is shown in Eq. (13):

$$
\begin{gathered}
P L=\frac{I \exp (d-e / t)}{a I^{2}+b I+C}-R \\
I_{C}=\frac{-[R b-\exp (d-e / t)] \pm \sqrt{[R b-\exp (d-e / t)]^{2}-4 R^{2} a C}}{2 R a}
\end{gathered}
$$

where $P L$ is net primary productivity, $R$ is carbon losses due to respiration and exudation, and $I_{c}$ is compensation photon flux density. In Fig. 11 compensation photon flux densities for the different temperatures obtained with algae from the 4 pre-treatments are shown. It can be seen that the compensation values for winter acclimated plants are above the estimated average winter photon flux densities. Even if these average values were assumed to be twice as high, it is clear from Fig. 11 that the compensation photon flux densities at the winter average temperature $\left(14.5^{\circ} \mathrm{C}\right)$ would still be higher.

From the results obtained it is possible to conclude that the changes in pigment contents during the course of the acclimation treatments were mainly random, except perhaps for chl a in the winter treatments. Apparently, in all treatments, and in spite of the initial differences, the final pigment contents converged to similar values. It is known that algae acclimated to lower irradiances increase their pigment contents and light harvesting efficiency (Falkowski 1991), but acclimation to higher temperatures has a similar effect (Davison 1991). This could perhaps explain the observed convergence in the pigment contents of the winter and summer acclimated plants. The absence of detectable differences among the pigment contents of plants acclimated to 9 and $13 \mathrm{~m}$ depth is probably due to the small photon flux density differences. It follows that the differences in photosynthetic efficiency between the winter and summer acclimations can seldom be explained from changes in pigment contents. Probably the observed differences were due to changes at 
other levels of the photosynthetic apparatus, such as the $\mathrm{CO}_{2}$ fixation, the electron transport or the cellular activities of Calvin cycle enzymes.

The results obtained suggest that long-term temperature effects can compensate long-term light effects Summer acclimated plants may have higher quantum efficiencies than winter acclimated ones. Due to the absence of seasonal light or temperature effects on $I_{\text {opt }}$ (Duarte in press) it is predictable that light saturated photosynthesis may reach higher values in summer than in winter acclimated plants, as was the case in the present work (Figs. 7 to 10). The higher respiratory rates of the winter acclimated plants (Table 2), along with their lower photosynthetic efficiencies, explain their higher compensation photon flux densities. This suggests that during winter a significant part of the subtidal Gelidium sesquipedale stands that can reach a $20 \mathrm{~m}$ depth will have a negative net productivity. In fact, the growth of plants acclimated to the winter conditions was not significantly different from zero ( $t$-test, $p<0.05$ ). The opposite was found to be true for summer acclimated plants.

The results reported in this study stress the importance of knowing the seasonal variability of the $P$-I curve parameters when modelling algal primary productivity. Further studies on the interaction of longterm light and temperature effects on photosynthesis seem to be required to fully understand the mechanisms that lead to the results obtained in this work.

Acknowledgements. This work was supported by JNICT (Ph.D grant No. $154-1 G$ ) and INETI. The authors thank C. Peneda for support of this research and L. Saldanha, L. Fonseca and $O$. Luis (LMG-IMAR) and F. Duarte (INETl) for making laboratory facilities available. Helpful comments of 4 anonymous reviewers on an earlier draft are also acknowledged.

\section{LITERATURE CITED}

Algarra P, Niell FX (1987) Structural adaptations to light reception in two morphotypes of Corallina elongata Ellis \& Solander. PSZN 1 Mar Ecol 8(3):253-261

Algarra P. Niell FX (1990) Short-term pigment response of Corallina elongata Ellis et Solander to light intensity. Aquat Bot 36:127-138

Beer S, Eshel A (1985) Determining phycoerythrin and phycocyanin concentrations in aqueous crude extracts of red algae. Aus J mar Freshwat Res 36:785-792

Beer S, Levy l (1983) Effects of photon fluence rate and light spectrum composition on growth, photosynthesis and pigment relations in Gracilaria sp. J Phycol 19:516-522

Cloern JE (1977) Effects of light intensity and temperature on Cryptomonas ovata (Cryptophyceae) growth and nutrient uptake rates. J Phycol 13:389-395

Davison IR (1991) Minireview. Environmental effects on algal photosynthesis: temperature. J Phycol 27:2-8

Dromgoole FI (1978a) The effects of $\mathrm{pH}$ and inorganic carbon on photosynthesis and dark respiration of Carpophyllum (Fucales, Phaeophyceae). Aquat Bot 4:11-22
Dromgoole FI (1978b) The effects of oxygen on dark respiration and apparent photosynthesis of marine macro-algae. Aquat Bot 4:281-297

Duarte P (1990) Determinaçāo da produtividade liquida da alga agarófita Gelidium sesqupedale. In: $1^{\circ}$ Encontro nacional sobre macroalgas marınhas. LNETI, Lisbon, p $97-105$

Duarte P (in press) A mechanistic model of the effects of light and temperature on algal primary productivity. Ecol Model

Duarte P. Ferreira JG (1993) A methodology for parameter estimation in seaweed productivity modelling. Hydrobiologia 260/261:183-189

Eilers PHC, Peeters JCH (1988) A model for the relationship between light intensity and the rate of photosynthesis in phytoplankton. Ecol Model 42:199-215

Eilers PHC, Peeters JCH (1993) Dynamic behaviour of a model for photosynthesis and photoinhibition. Ecol Model 69:113-133

Falkowski PG, LaRoche J (1991) Minireview. Acclimation to spectral irradiance in algae. J Phycol 27:8-14

Ferreira JG, Ramos L (1989) A model for the estimation of annual production rates of macrophyte algae. Aquat Bot $33: 53-70$

Fredriksen S, Rueness J (1989) Culture studies of Gelidium latifolium (Grev.) Born et Thur. (Rhodophyta) from Norway. Growth and nitrogen storage in response to varying photon flux density, temperature and nitrogen availability. Botanica mar 32:539-546

Gelder RJ, Osborne, BA (1989) Respuration and microalgal growth: a review of the quantitative relationship between dark respiration and growth. New Phytol 112:327-341

Hulbert SH (1984) Pseudoreplication and the design of ecological field experiments. Ecol Monogr 54:187-211

Keller AA (1989) Modeling the effects of temperature, light, and nutrients on primary productivity: an empirical and a mechanistic approach compared. Limnol. Oceanogr 34 : $82-95$

Khailov KM, Burlakova ZP (1969) Release of dissolved organic matter by marine seaweeds and distribution of their total organic production to inshore communities. Limnol Oceanogr 14:521-527

Kremer BP (1981) Aspects of carbon metabolism in marine macroalgae. Oceanogr mar Biol A Rev 19:41-94

Laws EA. Archie JW (1.981) Appropriate use of regression analysis in marine biology. Mar Biol 65:13-16

Littler MM (1979) The effects of bottle volume, thallus weight, oxygen saturation levels and water movement on apparent photosynthetic rates in marine algae. Aquat Bot $7: 21-34$

Littler MM, Arnold KE (1980) Sources of variability in macroalgal primary productivity: sampling and interpretative problems. Aquat Bot 8:141-156

Markager S (1993) Light absorption and quantum yield for growth in five species of marine macroalgae. J Phycol 29: $54-63$

Mead R, Curnow RN (1983) Statistical methods in agriculture and experimental biology. Chapman and Hall, London

Minitcheva GG, Eremenko TI (1986) Specific weight as a structural and functional characteristic of macrophytobenthos populations - a methodological approach. Biological lnstitute of the South Seas, Odessa (in Russian)

Perry JH (ed) (1950) Chemical Engineers Handbook, 3rd edn. McGraw Hill Book Company Inc, New York

Platt T, Gallegos CL, Harrison WG (1980) Photoinhibition of photosynthesis in natural assemblages of marine phytoplankton. J mar Res 38:687-701 
Potvin C, Lechowicz MJ (1990) The statistical analysis of ecophysiological response curves obtained from experiments involving repeated measures. Ecology $71: 1389-1400$

Rable A (1985) Active solar collectors and their applications Oxford University Press, Oxford

Ramus J, Beale SI, Mauzerall D (1976a) Correlation of changes in pigment content with photosynthetic capacity of seaweeds as a function of water depth. Mar Biol 37:231-238

Ramus J, Beale SI, Mauzerall D, Howard KL (1976b) Changes in photosynthetic pigment concentration in seaweeds as a function of water depth. Mar Biol 37:223-229

Ramus J, Lemons F, Zimmerman C (1977) Adaptation of lightharvesting pigments to downwelling light and the consequent photosynthetic performance of the eulittoral rockweeds Ascophyllum nodosum and Fucus vesiculosus. Mar Biol 42:293-303

Rowan SK (1989) Photosynthetic pigments of algae. Cambridge University Press, Cambridge

Sand-Jensen K (1988) Minimum light requirements for growth in Ulva lactuca. Mar Ecol Prog Ser 50:187-193

Santelices B (1978) Multiple interaction of factors in the distribution of some Hawaiian Gelidiales (Rhodophyta). Pacif Sci 32(2): 119-147

Santelices B (1988) Synopsis of biological data on the seaweed genera Gelidium and Pterocladia (Rhodophyta). FAO Fish Synopses 145

This article was submitted to the editor
Santos R, Duarte P (1991) Marine plant harvest in Portugal. J appl Phycol 3:11-18

Sharp GJ, Trembley DM (1985) A tagging technique for small macrophytes. Bot Mar 28:549-551

Sokal RR, Rohlf FJ (1981) Biometry. The principles and practice of statistics in biological research. WH Freeman \& Co, San Francisco

Talling JF, Driver D (1963) Some problems in the estimation of chlorophyll-a in phytoplankton. In: Proc Conference of Primary Productivity Measurement, Marine and Freshwater, Hawaii, 1961 TID - 7633. US Atomic Energy Comm, p 142-146

Torres M, Niell FX, Algarra P (1991) Photosynthesis of Gelidium sesquipedale: effects of temperature and light on pigment concentration, $\mathrm{C} / \mathrm{N}$ ratio and cell-wall polysaccharides. Hydrobiologia 221:77-82

Underwood AJ (1981) Techniques of analysis of variance in experimental marine biology and ecology. Oceanogr mar Biol A Rev 19:513-605

Vollenweider RA (1974) A manual on methods for measuring primary productivity in aquatic environments. Blackwell Scientific Publications, Oxford

Wing SR, Patterson MR (1993) Effects of wave-induced lightflecks in the intertidal zone on photosynthesis in the macroalgae Postelsia palmaeformis and Hedophyllum sessile (Paheophyceae). Mar Biol 116:519-525

Manuscript first received: February 3, 1994

Revised version accepted: January 23, 1995 